\title{
Fabrication and characterization copper/diamond composites for heat sink application using powder metallurgy
}

\author{
Zeinab Abdel Hamid ${ }^{1 *}$, Sayed F. Moustafa ${ }^{1}$, Fatma A. Morsy ${ }^{2}$, Nevien Abdel Atty Khalifa ${ }^{2}$, \\ Fatma Abdel Mouez ${ }^{1}$
}

${ }^{1}$ Central Metallurgical R \& D Institute, CMRDI, Cairo, Egypt; ${ }^{*}$ Corresponding Author: forzeinab@yahoo.com

${ }^{2}$ Faculty of Science, Chemistry department, Helwan University, Helwan, Egypt.

Received 27 July 2011; revised 30 August 2011; accepted 10 September 2011.

\section{ABSTRACT}

Copper composites reinforced with diamond particles were fabricated by the powder metallurgical technique. Copper matrix and diamond powders were mixed mechanically, cold compacted at 100 bar then sintered at $900^{\circ} \mathrm{C}$. The prepared powders and sintered copper/diamond composites were investigated using $X$-ray diffraction (XRD) and scanning electron microscope equipped with an energy dispersive X-ray analysis (SEM/EDS). The effect of diamond contents in the $\mathrm{Cu} /$ diamond composite on the different properties of the composite was studied. On fracture surfaces of the Cu/uncoated diamond composites, it was found that there is a very weak bonding between diamonds and pure copper matrix. In order to improve the bonding strength between copper and the reinforcement, diamond particles were electroless coated with NiWB alloy. The results show that coated diamond particles distribute uniformly in copper composite and the interface between diamond particles and $\mathrm{Cu}$ matrix is clear and well bonded due to the formation of a thin layer from $\mathrm{WB}_{2}$, $\mathrm{Ni}_{3} \mathrm{~B}$, and $\mathrm{BC}_{2}$ between $\mathrm{Cu}$ and diamond interfaces. The properties of the composites materials using coated powder, such as hardness, transverse rupture strength, thermal conductivity, and coefficient of thermal expansion (CTE) were exhibit greater values than that of the composites using uncoated diamond powder. Additionally, the results reveals that the maximum diamond incorporation was attained at 20 $\mathrm{V}_{\mathrm{f}} \%$. Actually, $\mathrm{Cu} / 20 \mathrm{~V}_{\mathrm{f}} \%$ coated diamond composite yields a high thermal conductivity of $\mathbf{4 3 0}$ $\mathrm{W} / \mathrm{mK}$ along with a low coefficient of thermal expansion (CTE) $6 \times 10^{-6} / \mathrm{K}$.
Keywords: Powder Metallurgy; Ceramic-Matrix Composites (CMCs); Ceramics; Coating;

Electroless

\section{INTRODUCTION}

In order to dissipate the heat generated in electronic packages effectively, suitable materials must be selected as heat spreaders and heat sink [1-6]. The ideal material working as heat sink and heat spreader should have a low coefficient of thermal expansion (CTE) and a high thermal conductivity. Copper as it has the highest thermal conductivities in metal, has been used for decades as the material of choice as heat sink for semiconductor electronic packages. Unfortunately, copper has become a bottleneck in removing heat from semiconductor devices, and its thermal conductivity becomes not enough to dissipate the heat generated from the new generation of semiconductor components. In addition to bulk thermal conductivity which must be removed, thermal expansion coefficients of semiconductors of silicon or gallium arsenide are low compared to other materials and much smaller than that of copper which is usually used as a heat sink for semiconductors. The differences in coefficient of thermal expansion properties leads to formation of stresses, which can lead to the component becoming distorted, detached or even fractured. Stresses may form during production of the semiconductor chip, specifically during the cooling phase from the soldering temperature to room temperature. However, temperature fluctuations also occur when the package is operating, ranging from $-50^{\circ} \mathrm{C}$ to $200^{\circ} \mathrm{C}$, which can lead to thermomechanical stresses. As copper and other metals exhibit thermal expansion rates that are an order of magnitude greater than those of silicon and gallium arsenide, it is problematic to attach these metals to semiconductor chips. In fact, many packaging solutions sacrifice on 
thermal conductivity, choosing less efficient heat conductors such as ceramics in order to address this issue [6].

There is a great demand for a new material to be used as heat sink substrate. This new material should have high thermal conductivity greater than that of copper (i.e. as great as possible) in order to dissipate the high heat generated from the semiconductor component during operation, and in the same time its coefficient of thermal expansion must match as closely as possible to that of the semiconductor component. This new material could be developed by means of composite materials such as $\mathrm{Cu} /$ diamond composite. Since diamond is characterized by high thermal conductivity about 6 times that of copper but its disadvantage that its thermal expansion is smaller than that of semiconductors. So by adding copper to diamond we can have the required characteristics by controlling the percentages of copper to diamond [7-9]. The major problems encountered with "diamond on copper" synthesis are the low nucleation density, film cracking, and poor wetability. When diamond particles are embedded in a copper matrix, the interface plays a crucial role in determining the thermal conductivity, the CTE and also the mechanical properties of the composite. An ideal interface should provide good adhesion and minimum thermal boundary resistance.

It is well known that alloying of copper with a strong carbide diamond forming element promotes wetting and bonding of diamond. Even in the case of solid phase bonding (e.g. hot pressing), high bonding strength was observed for copper alloys with minor additions of carbides from (Ti, Cr, B or Zr) [10,11]. Chromium or tungsten is believed to be a good promoter due to its abilities to inhibit bulk copper formation, to improve copper thermal stability and to increase copper dispersion. The main objective of this investigation is to synthesize and characterize $\mathrm{Cu}$ /diamond composite materials for electronic application obtained by powder metallurgy technique. Coating diamond particles using electroless technique added to the copper matrix to fabricate $\mathrm{Cu}$ /diamond composite has been investigated. Finally, the properties of $\mathrm{Cu}$ /coated diamond composites were compared with the same materials containing uncoated diamond.

\section{EXPERIMENTAL PROCUDURES}

\subsection{General}

In the present work, the fabrication of $\mathrm{Cu} /$ diamond composites using powder metallurgy technique was investigated in detail. The investigated diamond powders of micron grain sizes $(20-40 \mu \mathrm{m})$ type RVD were supplied by Polaris Diamond Powder Co., Ltd. The diamond powder was electroless coated with NiWB. Cop- per powder using in this study has been fabricated using electroless technique.

\subsection{Surface Treatment for Diamond and Electroless NiWB Plating}

As the diamond surface has higher interface energy, the adhesion of surface with the coating layer is bad, and it makes the diamond shatter easily. For solving this, the diamond surface must be treated and activated to improve the coating adhesion. The following steps were used for surface treatment.

Washing by acetone (30 min.); etching by acidic solution using $50 \% \mathrm{HNO}_{3}$; sensitization using stannous chloride solution; activation using palladium chloride solution; then immersed in the plating solution [12].

The diamond after sensitization and activation were chemically coated with NiWB. The chemical composition and the operating conditions of the plating solution were illustrated in Table 1. Additionally, the chemical composition and the operating conditions for producing the copper powder using electroless technique were illustrated in Table 2. Analytical reagents and distilled water were used to prepare the plating solutions.

Table 1. Chemical composition and operating conditions of electroless NiWB plating solution.

\begin{tabular}{cc}
\hline Composition & $\begin{array}{c}\text { Concentration, } \mathrm{gl}^{-1} \\
\text { NiWB }\end{array}$ \\
\hline Nickel sulphate & 10 \\
sodium citrate & 20 \\
Dimethyl amine borane (DMAB) & 0.4 \\
sodium Tungestate & 20 \\
\hline \multicolumn{2}{c}{ Operating conditions } \\
\hline Temperature, ${ }^{\circ} \mathrm{C}$ & 85 \\
$\mathrm{pH}$ & 6.5 \\
Time, hrs & 2 \\
\hline
\end{tabular}

Table 2. The chemical composition and the operating conditions of electroless copper solution.

\begin{tabular}{cc}
\hline Composition & Concentration $\mathrm{gl}^{-1}$ \\
\hline Copper sulphate & 35 \\
Sodium potassium tartrate & 170 \\
Sodium hydroxxide & 50 \\
Formaline & $200 \mathrm{mlL}^{-1}$ \\
\hline \multicolumn{2}{c}{ Operating conditions } \\
\hline Temperature, ${ }^{\circ} \mathrm{C}$ & $11-13$ \\
\hline
\end{tabular}




\subsection{Composites Production}

The amount of powder and coating thickness must be controlled during the production of composite. If a too large amount of diamond or a too thick coating for the functional layer is used the thermal conductivity of the copper matrix material will be reduced very severe. The copper powders were mixed with the diamond particles to prepare composites then milled for $20 \mathrm{~min}$, compacted under the pressure 100 bar then sintered at $900^{\circ} \mathrm{C}$ for 1 hr using hydrogen atmosphere.

\subsection{Analysis and Characterizations}

Scanning electron microscope (SEM) with a link energy dispersive X-ray spectroscopy (EDS) detector attachment, model JEOL, JSM-5410, were used to assess the surface morphology, particle size, particle shape, agglomeration of particles and the compositions of the various $\mathrm{Cu}$ /diamond composites. For SEM, the dry powder was dusted onto a carbon tape, which was stuck onto the copper holder disk of the microscope, gently blown with compressed air before introducing into the microscope chamber.

The phase identification was determined using X-ray diffraction PANalytical X'pert PRO (45 kv/40 mA) advanced with $\mathrm{Cu}$ target $(\lambda=1.54 \mathrm{~A} 0)$. The boron content of the NiWB thin film deposited was determined by inductively coupled plasma-mass spectrometer (ICP-MS) after dissolving the deposited layer in nitric acid solution.

\subsection{The Densities Measurements}

The densities of the sintered powders were measured according to MPIF Standards 42, 1998, using Archimedes rule. The density $(\delta)$ of the samples was calculated according to the following formula $[13,14]$ :

$$
\delta=W_{a} /\left(W_{a}-W_{w}\right) \quad \mathrm{gm} / \mathrm{cm}^{3}
$$

where $W_{a}$ and $W_{w}$ are the weights in air and water respectively.

\subsection{The Electrical Resistivity Measurements}

The electrical resistivity of the sintered materials was measured using the four-probe method by using Omega CL 8400 micrometer device. The rectangular sintered specimen was placed in a specially designed jig for making the electrical connection. Measurements were taken for the longitudinal and the transverse directions of the sample. The resistivity $(\rho)$ was calculated according to the following equation by using High Precision Microohmmeter.

$$
\rho=(R \cdot A) / L
$$

where, $R$ is the resistance in micro ohm, $L$ is the measured length in $\mathrm{cm}, \mathrm{A}$ is the cross section area in $\mathrm{cm}^{2}$, and $\rho$ is the resistivity in $\mu \cdot \Omega \cdot \mathrm{cm}$.

\subsection{The Macrohardness Measurements}

The macrohardness values of the investigated materials were measured as the average of 5 readings over the surface of the specimens using Vicker's macrohardness Test type HPV $30 \mathrm{~A}$ and the using load was $5 \mathrm{~kg}$ for $15 \mathrm{~s}$.

\subsection{Transverse Rupture Strength (TRS) Measurements}

The rupture test was performed using compression testing machine and a test fixture, according to MPIF Standard 41. All the samples of the powders were compacted into rectangular compacts of dimension of $(30 \times$ $10 \times 6) \mathrm{mm}^{3}$. In the transverse rupture fixture, the test bar was placed centrally located and perpendicular to the supporting rods with the top up. The fixture with the test bar was placed between the plates of the compression testing machine and the load was applied at constant rate of $2.5 \mathrm{~mm} / \mathrm{min}$, until the test bar fractured. The transverse rupture strength for sintered samples was calculated according to the following expression [13]:

$$
T R S=\frac{3 P L}{2 t^{2} W}
$$

where: $T R S=$ Transverse rupture strength in N/mm

$P=$ Fracturing (rupture) load $(\mathrm{N})$

$L=$ the distance between the supporting rods (25.4 $\mathrm{mm}$ )

$t=$ the thickness of the sample in (mm)

$W=$ the width of the sample in (mm)

\subsection{Coefficient of Thermal Expansion (CTE)}

CTE was measured with a Netzsch dilatometer model $402 \mathrm{C}$ push rod. The samples were tested in open air between $25^{\circ} \mathrm{C}$ and $160^{\circ} \mathrm{C}$ at a heating rate of $3 \mathrm{~K} / \mathrm{min}$. Further on, the reproducibility was checked by measuring the same sample twice. The system was calibrated with a copper standard prior to the sample test run. Coefficient of thermal expansion (CTE) value at a given temperature was calculated from the thermal expansion curves (change in length versus temperature) recorded during heating up the specimen from room temperature up to $160^{\circ} \mathrm{C}$, according to this relationship:

$$
C T E=\frac{\partial}{\partial T}\left(\frac{\Delta L}{L}\right)
$$

where $L$ represents the original length of the specimen 
and $\Delta L$ stands for the length change after a thermal cycling.

\subsection{Thermal Conductivity}

The thermal conductivity was calculated from electrical resistivity measurement using Wiedemann and Franz equation which derived a relation equation between the thermal and electrical conductivities [15]. The Wiedemann-Franz equation is as follows:

$$
\frac{\lambda}{\sigma T}=\frac{\pi^{2} k_{B}^{2}}{3 e^{2}}=L=2.443 \times 10^{-8} \mathrm{~J} \Omega / \mathrm{K}^{2} \mathrm{~s}
$$

where, $\lambda$ is thermal conductivity $(\mathrm{W} / \mathrm{mK}), \sigma$ is electrical conductivity $\mu \cdot \Omega \cdot \mathrm{cm}^{-1}, T$ is absolute temperature in degree Kelvin, $\mathrm{KB}$ is Boltzmann constant, and $L$ is Lorentz number.

\section{RESULTS AND DISCUSSION}

\subsection{Surface Treatment of Diamond Powders Surface Cleaning and Etching}

The coating process of diamond powders is highly dependent on the pre-treatment of the powders themselves. The first pretreatment step is to remove any foreign matter may be existed from the reinforcement powders. Acetone was used to remove any organic matter, such as grease or oil, and finally used $50 \% \mathrm{HNO}_{3}$ for further cleaning the powder surfaces and also to etch their surfaces. This pretreatment increases the ability of diamond surface to be coated, increases the homogeneity of the coating film and improves the adhesion of coating layer. Although the coating bath is the most visible and complex, any process problem is almost not due to the chemistry of the bath itself, but is more likely due to the pre-treatment of the surface of the substrate.

\section{Activation (Metallization) of Diamond Surfaces}

The main purpose of the metallization process for diamond powders is to etch and provide active sites that can react with the activators as well as to convert the hydrophobic to hydrophilic surface. Adding sensitized powders to the activation bath, the tin ions that are adsorbed on the diamond surfaces, reduce the palladium ions in the activation step according to the following equation:

$$
\mathrm{Sn}^{+2}+\mathrm{Pd}^{+2} \rightarrow \mathrm{Sn}^{+4}+\mathrm{Pd}^{0}
$$

This step results in imparting a uniform surface film to the diamond powders, which ensures uniform adsorption of subsequent coating and therefore promotes better coating [16].

\subsection{NiWB Electroless Plating}

The coatings are deposited on the surface of diamond found in the solution once its $\mathrm{pH}$ value becomes 6.5 and its temperature $85^{\circ} \mathrm{C}$. NiWB coating process used in this investigation is a chemical reduction process by dimethyl amine borane (DMAB) which served as a reducing agent to supply electrons for the reduction process. The diamond powders coated with NiWB are investigated by scanning electron microscope and the X-ray diffraction. The scanning electron micrograph of the diamond coated is shown in Figure 1. Continuous coating is seen on the surfaces of diamond. Figure 2 illustrated the chemical composition and the obtained average data of the coated layer using EDS. It was interesting to note that the nickel content of the deposit is higher than the tungsten content, suggesting an anomalous behavior that involves a preferential deposition of electrochemically less noble in the deposit. Saito et al. [17] have also observed this anomaly and suggested that the low overvoltage for nickel deposition is the reason for its

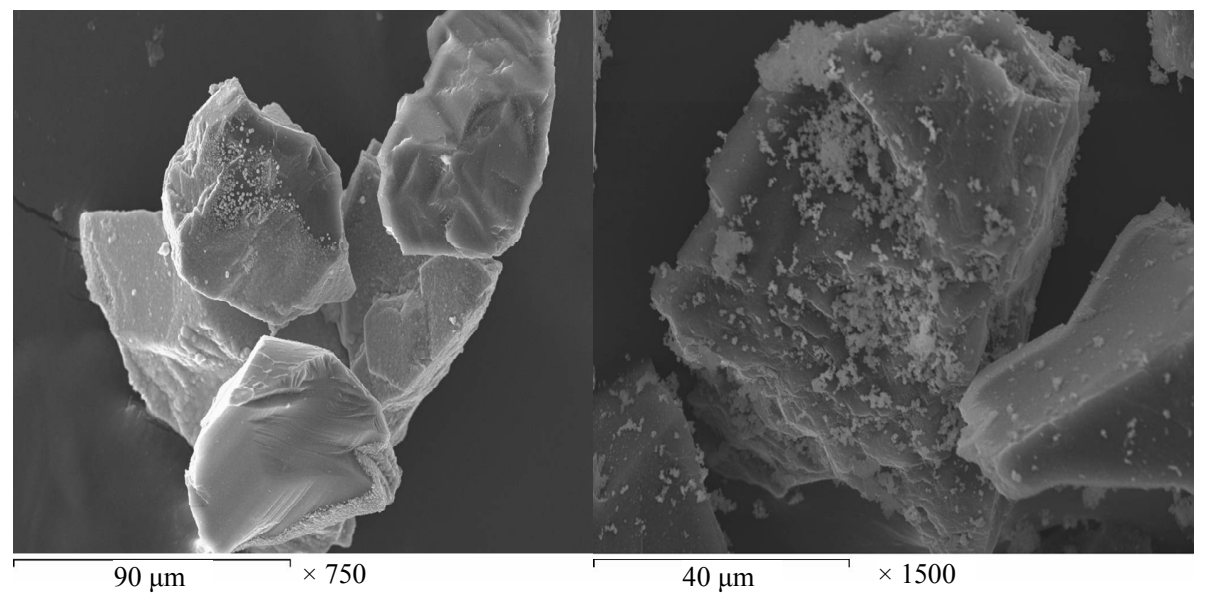

Figure 1. SEM image for the diamond coated with NiWB film. 


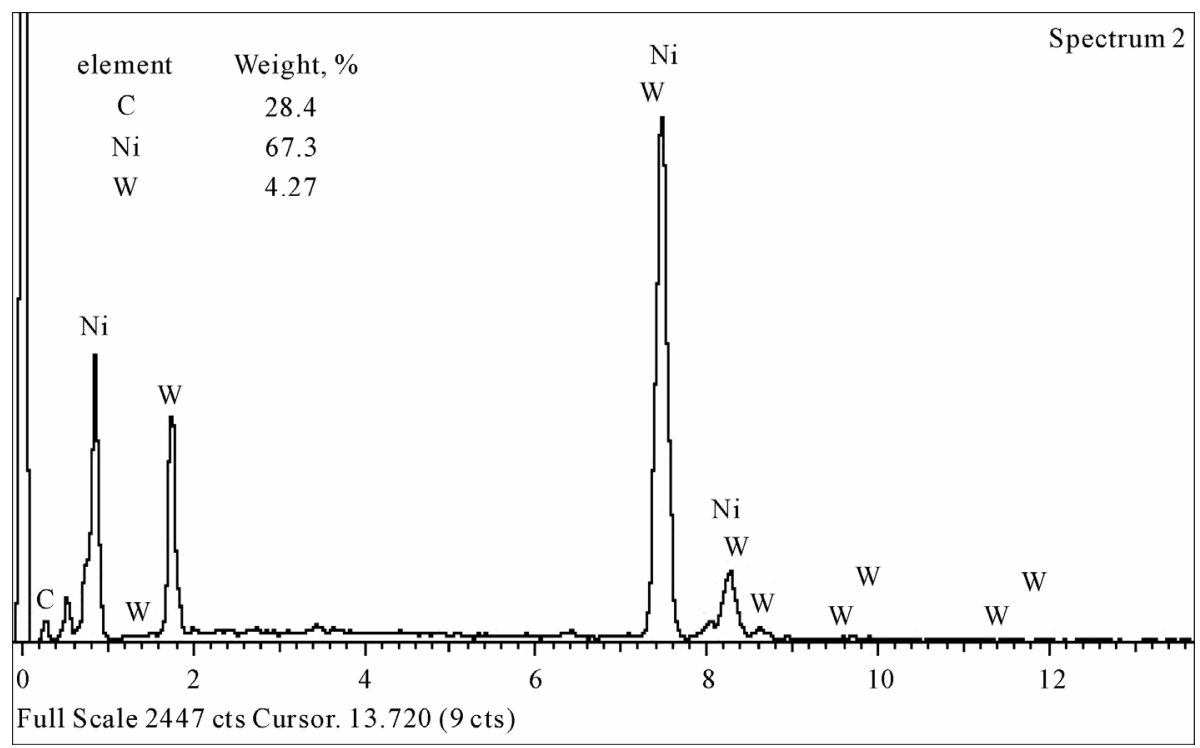

Figure 2. EDS analysis of the diamond coated with electroless NiWB.

preferential deposition in the electroless deposit. The B content in the film was determined by inductively coupled plasma-mass spectrometer (ICP-MS). The analysis proved that the B content in the NiWB film was $5 \mathrm{wt} \%$. View Within Article

XRD pattern for uncoated and coated diamond before and after heat treatment is illustrated in Figure 3. Figure 3(a) shows the peaks at $2 \theta$ of 440 and 750 which attributed to the pure diamond powder, while XRD pattern for diamond powder coated with NiWB as a deposit (Figure 3(b)) is seen the presence of sharp peak represent the presence of $\mathrm{W}$ at $35^{\circ}$ and peaks represent the presence of diamond at $75^{\circ}$ and broad peak with low intensity at $45^{\circ}$ represent the deposition of $\mathrm{Ni}$ alloy in amorphous structure. When the coated powders after heat treatment under reducing atmosphere at $900^{\circ} \mathrm{C}$ for $1 \mathrm{hr}$ were examined by XRD in order to find out any reaction, the pattern reveals that the amorphous coated converted to crystalline one. Crystallization induced by heating was confirmed by the appearance of diffraction lines corresponding to $\mathrm{WB}_{2}$ at $2 \theta$ of $37^{\circ}, \mathrm{BC}_{2}$ at $75.5^{\circ}, \mathrm{Ni}_{3} \mathrm{~B}$ at $45^{\circ}$ and $\mathrm{C}$ at $41.5,51,54.5$ and $60^{\circ}$ as those indicated in Figure 3(c).

The mechanism of electroless $\mathrm{NiB}$ has been studied by many researchers $[18,19]$. Nevertheless, the mechanism of formation of NiWB remains unclear. In traditional $\mathrm{NiB}$ solution, the acid hydrolysis of DMAB occurs according to the following equations [17]:

$$
\begin{gathered}
\mathrm{R}_{2} \mathrm{NHBH}_{3} \rightarrow \mathrm{R}_{2} \mathrm{NH}+\mathrm{BH}_{3}+\mathrm{H}_{2}+\mathrm{H}^{+} \\
\rightarrow \mathrm{R}_{2} \mathrm{NH}^{+}+\mathrm{B}+5 / 2 \mathrm{H} \\
\left(\mathrm{CH}_{2}\right)_{3} \mathrm{NHBH}^{3}+3 \mathrm{H}_{2} \mathrm{O}+\mathrm{H}^{+} \\
\rightarrow\left(\mathrm{CH}_{2}\right)_{3} \mathrm{NHBH}^{2+}+\mathrm{H}_{3} \mathrm{BO}_{3}+3 \mathrm{H}
\end{gathered}
$$

Most authors believe that the major species supplying electrons for metal-ion reduction is $\mathrm{BH}_{3} \mathrm{OH}^{-}$. The hydrolysis investigation of DMAB shows that hydrolysis is pronounced at $\mathrm{pH}<5$. So, a significant amount of DMAB is wasted by the hydrolysis, and consequently the electroless deposition in this range should be avoided [20,21]. In the $\mathrm{pH}$ region above 5 , the consumption of DMAB by hydrolysis approaches a minimum. Mallory proved that the rate of $\mathrm{Ni}$ deposition increases with an increase in DMAB for all investigated $\mathrm{pH}$ values within the range 6 to 11 [20]. However, it should be noted that an increase in $\mathrm{pH}$ within this range leads to a decrease in the rate of $\mathrm{Ni}$ deposition. This can be attributed to the increase in the solution stability (probably because of the tendency to hydrolyze at very high $\mathrm{pH}$ ). Under these conditions, the reduction reaction may start in the bulk solution and the rate of deposition decreases. Consequently, the deposition efficiency decreases. Additionally, Mallory suggested that the preferred operating $\mathrm{pH}$ range for Ni deposition with DMAB is 6 to 7 (near neutral) [21]. Generally, DMAB has three active hydrogen atoms bonded to the boron, and theoretically should reduce three metal ions (such as Ni) for each ion of $\mathrm{BH}_{3} \mathrm{OH}^{-}$.

$$
\mathrm{BH}_{3} \mathrm{OH}^{-}+3 \mathrm{Ni}^{2+}+2 \mathrm{H}_{2} \mathrm{O} \rightarrow 3 \mathrm{Ni}+\mathrm{B}(\mathrm{OH})_{3}+5 \mathrm{H}^{+}
$$

The boron reduction can be represented by the following reaction:

$$
\left(\mathrm{CH}_{2}\right)_{3} \mathrm{NH}+2 \mathrm{BH}_{3}+\mathrm{H}^{+} \rightarrow\left(\mathrm{CH}_{2}\right)_{3} \mathrm{NH}^{2+}+2 \mathrm{~B}+3 \mathrm{H}_{2}(5)
$$

The tungsten deposition mechanism itself is not clear yet. There are some proposed models that explain the fact that tungsten cannot be deposited either electrochemically or chemically by itself, but it can be deposited 

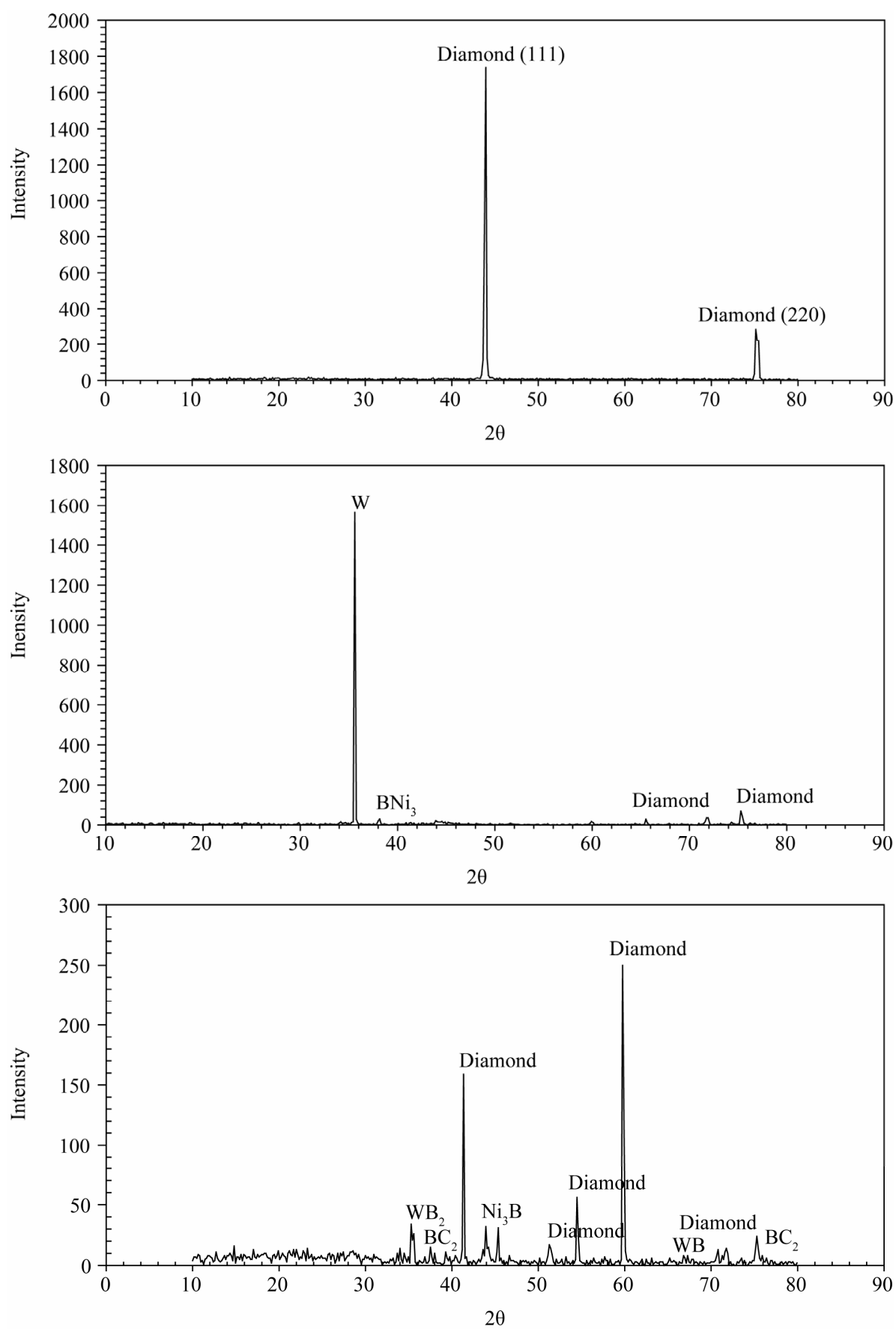

Figure 3. X-ray diffraction for diamond uncoated and coated with NiWB where, (a) diamond pure, (b) diamond coated before heat treated and (c) diamond coated after heat treatment at $900^{\circ} \mathrm{C}$.

with iron group metals [22]. This mechanism should take into consideration the $\mathrm{pH}$ and that the metals are complexes with the citrate. In the simplest case, this ion should have the formula $\left[\left(\mathrm{WO}_{4}\right) \text { (cit) }\right]_{\mathrm{x}-5}$ but this is, however, unstable. Several protonated forms of this complex are known, such as $\left[\left(\mathrm{WO}_{4}\right)(\mathrm{cit})(\mathrm{H})_{\mathrm{x}}\right]_{\mathrm{x}-5}$, where $\mathrm{x}$ can assume values of $1-3$. The reduction of these ions can be presented as:

$$
\mathrm{WO}^{2+}+2 \mathrm{H}_{2} \mathrm{O}+6 \mathrm{e}^{-} \rightarrow \mathrm{W}+4 \mathrm{OH}^{-}
$$

\subsection{Composites Fabrication}

Consolidation of metallic powders is mainly carried out using compaction followed by sintering. Sintering is 
a thermal process which increases the strength of a powder mass by bonding adjacent particles via diffusion or related atomic level events. As a result of this operation, the material acquires the required physical and mechanical properties. Most of the properties of a powder compact are improved with sintering. All the prepared composites were investigated by the SEM, and exposed to different physical and mechanical tests.

In order to make clear the difference in wetability of un-coated and coated diamond with $\mathrm{Cu}$ matrix, the surface morphologies of the sintered materials with different volume fraction diamond mixed with copper were observed by SEM. Figures 4(a)-(f) illustrate the dispersion of uncoated or coated diamond particles in the copper matrix. One can notice that the distribution of uncoated diamond (Figures 4(a)-(c)) or coated diamond (Figures 4(d)-(f)) increases with increasing diamond $\mathrm{V}_{\mathrm{f}} \%$ in the composite. The $\mathrm{Cu} /$ coated diamond composite has low porosity than $\mathrm{Cu}$ /un-coated diamond composite. Additionally, the distribution of diamond in the composite made from $\mathrm{Cu}$ /coated diamond powders is more uniform with good wetability than those of the composite made from $\mathrm{Cu} /$ uncoated diamond powders. Since the uncoated diamond particles are easy to be stripped off during mechanical polishing, small pits are left on the surface of samples. While, the composite made from $\mathrm{Cu} /$ coated diamond powders has low porosity content due to less $\mathrm{Cu}-\mathrm{C}$ contacts during sintering, and the metallic binders (coated film) decrease all the existing cavities between $\mathrm{Cu}$ particles. The uniform distribution and a maximum value of the diamond in the composite were observed at $20 \% \mathrm{~V}_{\mathrm{f}}$.

\subsection{Characterizations of the Fabricated Composites}

\subsubsection{Densities Calculation}

The density of the copper/diamond composite is one of the most important properties due to its effect on the other properties. It is very sensitive to composition and porosity in the sample and is widely used as a quality control test. The densities and relative densities of the sintered copper/diamond composite materials with different diamond $\mathrm{V}_{\mathrm{f}} \%$ are reported in Table 3 . The relative density of the sintered materials was calculated according to the following formula:

$$
\text { Relative density }(R d \%)=(\delta s / \delta t) \%
$$

where $\delta s$, and $\delta t$ are the densities of sintered density (actual density) and theoretical density respectively.

The data reveals that the density of composite materials containing coated diamond with NiWB has higher value than that composite containing uncoated diamond
Table 3. The densities and relative densities percentage of the sintered materials with different $\mathrm{V}_{\mathrm{f}} \%$ of diamond.

\begin{tabular}{|c|c|c|c|}
\hline Investigated composites & $\rho s$ & $\rho t$ & $R d \%$ \\
\hline \multicolumn{4}{|l|}{$\begin{array}{l}\mathrm{Cu} / \text { uncoated diamond with } \\
\text { different } \mathrm{V}_{\mathrm{f}} \%\end{array}$} \\
\hline 10 & 5.78 & 8.33 & 69.46 \\
\hline 15 & 5.86 & 8.045 & 72.25 \\
\hline 20 & 6.30 & 7.76 & 81.18 \\
\hline 30 & 6.66 & 7.19 & 60.00 \\
\hline \multicolumn{4}{|c|}{$\begin{array}{l}\mathrm{Cu} / \text { coated diamond with NiWB } \\
\text { with different } \mathrm{V}_{\mathrm{f}} \%\end{array}$} \\
\hline 10 & 6.27 & 8.33 & 88.6 \\
\hline 15 & 6.08 & 8.04 & 82.29 \\
\hline 20 & 5.50 & 7.76 & 99.7 \\
\hline 30 & 4.50 & 7.19 & 92.6 \\
\hline
\end{tabular}

particle. This is can be attributed to the excellent wetability between $\mathrm{Cu}$ matrix and coated diamond than in case of composite containing uncoated diamond due to high solubility of $\mathrm{Ni}$ in $\mathrm{Cu}$. Coated film is used as a bonding matrix because its wetting or capillary action during solid phase sintering allows the achievement of high densities; this improvement could be attributed to the ability of $\mathrm{B}$ and $\mathrm{W}$ to form carbide phases as shown in XRD analysis (Figure 3). XRD pattern can't prove the formation of tungsten carbide phase owing to low concentration of $\mathrm{W}$ compared to the concentration of $\mathrm{Ni}$ in the coated layer or carbon of the substrate. This results agreement with Q. Sun [9] who proved that pure liquid copper does not wet diamond, while well in presence of carbide which promotes wetting and bonding of diamond.

\subsubsection{Hardness Measurements}

Hardness measurements were used to investigate the strengthening effect of diamond particles as a reinforcement material and to distinguish the surface imperfection. Table 4 illustrates the hardness of the investigated composite materials. As can be seen, hardness of sintered materials made from coated diamond is higher than those made of uncoated diamond powders. Also hardness increases with increasing $\mathrm{V}_{\mathrm{f}} \%$ of diamond powder in the matrix. It is evident that $\mathrm{Cu}-20 \mathrm{~V}_{\mathrm{f}} \%$ coated diamond composites have the highest hardness values of all investigated composites, not only because of the strengthening effect of diamond but also due to the high density and low porosity content. While, in the case of the uncoated diamond, there is no any adhesion 


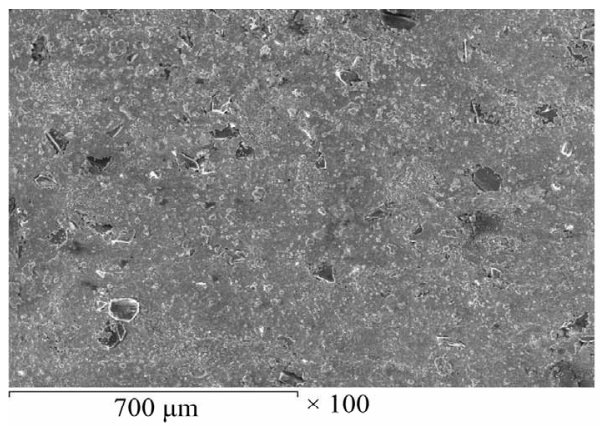

(a)

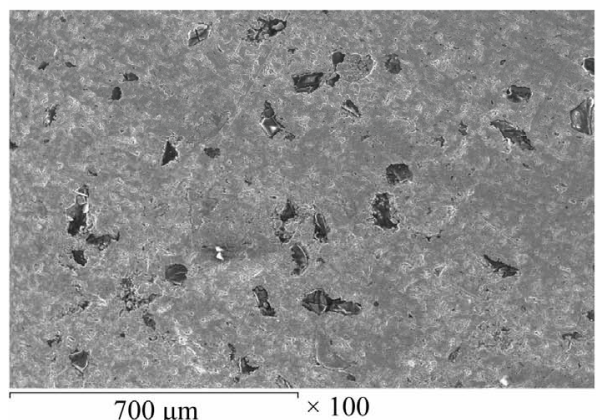

(c)

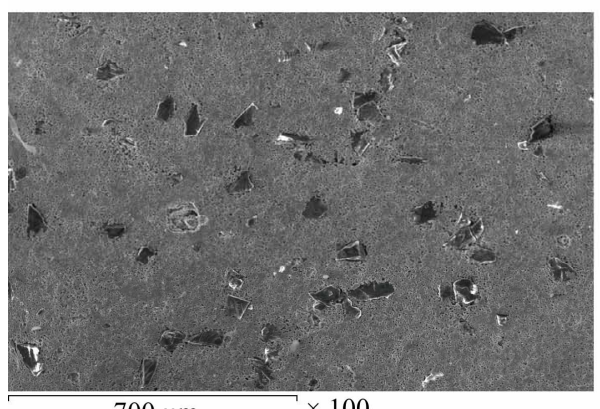

(e)

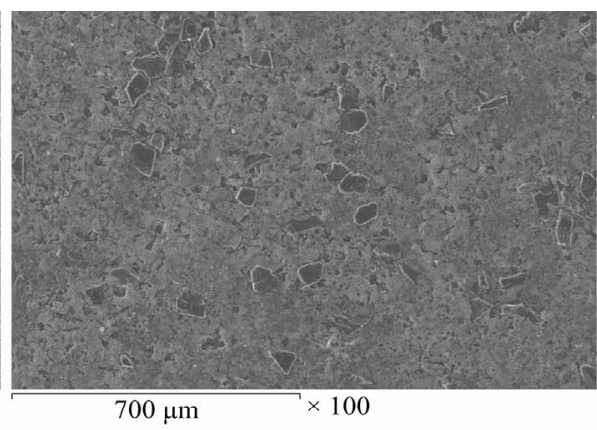

(b)

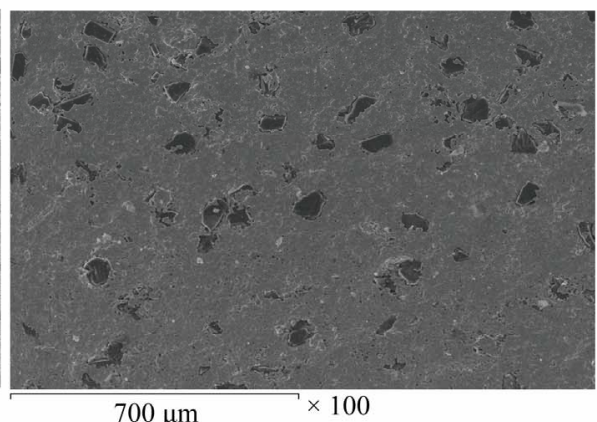

(d)

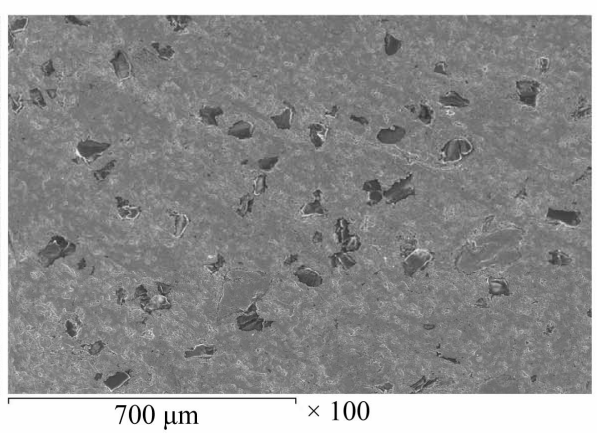

(f)

Figure 4. Surface morphologies of the as-polished $\mathrm{Cu}$ /uncoated diamond and $\mathrm{Cu} / \mathrm{NiWB}$ coated diamond composites prepared by $\mathrm{PM}$ technique containing different $\mathrm{V}_{\mathrm{f}} \%$ diamond where: (a)-(c) $\mathrm{Cu} / 10,20,30 \mathrm{~V}_{\mathrm{f}} \%$ uncoated diamond respectively and (d)-(f) $\mathrm{Cu}-10,20,30$ $\mathrm{V}_{\mathrm{f}} \%$ NiWB coated diamond.

or bond between the diamond and the copper matrix which causes the formation of pores in the final composite and hence showed low hardness.

\subsubsection{Electrical Conductivity Measurements}

The electro friction materials that exposed to high current densities or high voltages are produced from a composite material that having high electrical and thermal conductivities. Copper/diamond composite has a good sliding, antifriction properties, and high electrical and thermal conductivity [23]. The measured resistivity was converted to electrical conductivity IACS\% (International Annealed Copper Standard) according to the ASTM standard B 193-72.

The results of electrical resistivity measurements of the fabricated composites are shown in Table 5. It can be noticed that the electrical resistivity for all investigated $\mathrm{Cu} /$ diamond composites decreases with increasing $\mathrm{V}_{\mathrm{f}} \%$ of diamond up to $20 \mathrm{~V} \%$ and then slightly increase. At the same time, the electrical resistivity for the composite fabricated from coated diamond with NiWB is lower than that of composite fabricated from uncoated diamond. This can be rationalized by the high porosity of the $\mathrm{Cu}$ /uncoated diamond composite. This porosity was resulted from the weak bond between diamond and the $\mathrm{Cu}$ matrix as shown in Figure 4. This in turn, creates voids, which decreases the mobility of the free electron causing high resistivity $[24,25]$. The electrical conductivity is directly affected by porosity, the greater the void content the lower is the electrical conductivity. While, in 
Table 4. The Vicker Macro-Hardness values of the investigated composites.

\begin{tabular}{cc}
\hline Investigate Composites & Hardness Values, HV \\
\hline Pure copper & 52.00 \\
\hline $\mathrm{Cu} /$ uncoated diamond & \\
$\mathrm{Cu} / 10 \mathrm{~V} \%$ uncoated diamond & 55.00 \\
$\mathrm{Cu} / 15 \mathrm{~V} \%$ uncoated diamond & 55.00 \\
$\mathrm{Cu} / 20 \mathrm{~V} \%$ uncoated diamond & 56.00 \\
$\mathrm{Cu} / 30 \mathrm{~V} \%$ uncoated diamond & 52.00 \\
$\mathrm{Cu} / \mathrm{coated}$ diamond with NiWB & \\
$\mathrm{Cu} / 10 \mathrm{~V} \%$ coated diamond & 66.35 \\
$\mathrm{Cu} / 15 \mathrm{~V} \%$ coated diamond & 77.04 \\
$\mathrm{Cu} / 20 \mathrm{~V} \%$ coated diamond & 87.45 \\
$\mathrm{Cu} / 30 \mathrm{~V} \%$ coated diamond & 74.24 \\
\hline
\end{tabular}

Table 5. The electrical resistivity of the investigated composites.

\begin{tabular}{ccc}
\hline \multirow{2}{*}{ Investigate Composites } & \multicolumn{2}{c}{ electrical resistivity } \\
\cline { 2 - 3 } & Resistivity $(\mu \cdot \mathrm{cm})$ & IACS $\%$ \\
\hline Pure copper chemically deposited & 2.1 & 82.00 \\
$\mathrm{Cu} /$ uncoated diamond & & \\
$\mathrm{Cu} / 10 \mathrm{~V} \%$ uncoated diamond & 2.33 & 74.00 \\
$\mathrm{Cu} / 15 \mathrm{~V} \%$ uncoated diamond & 2.085 & 82.5 \\
$\mathrm{Cu} / 20 \mathrm{~V} \%$ uncoated diamond & 1.96 & 87.75 \\
$\mathrm{Cu} / 30 \mathrm{~V} \%$ uncoated diamond & 2.00 & 86.00 \\
$\mathrm{Cu} / \mathrm{coated}$ diamond with NiWB & & \\
$\mathrm{Cu} / 10 \mathrm{~V} \%$ coated diamond & 1.78 & 97.00 \\
$\mathrm{Cu} / 15 \mathrm{~V} \%$ coated diamond & 1.74 & 99.00 \\
$\mathrm{Cu} / 20 \mathrm{~V} \%$ coated diamond & 1.73 & 99.40 \\
$\mathrm{Cu} / 30 \mathrm{~V} \%$ coated diamond & 1.75 & 98.30 \\
\hline
\end{tabular}

case of $\mathrm{Cu} /$ coated diamond composites the pores is low due to the presence of a metallic bond between the coated layer on the diamond surface and the copper matrix. The NiWB coated diamond composite has the highest and more conductive sample due to the following reasons:

- The highest density and lowest porosity of the materials.

- The good adhesion force between the carbide coating with diamond surface on one side and the copper matrix on the other side.

- The presence of a carrier layer at the interface be- tween the copper matrix and the diamond, which transfer the high electrical conductivity properties of the copper to the diamond.

- The high hardness of carbide layers which increase the effect of compaction pressure on $\mathrm{Cu}$-matrix on one side and protect diamond from fragmentation on the other side.

\subsubsection{Transverse Rupture Strength (TRS)}

Transverse rupture strength (TRS) is the most common method for determining the fracture strength of composite materials; it is the maximum stress that is encountered during a three-point bending test. In the same time the TRS testing method is more suitable than the tensile measurement for determining the strength of materials processed by powder metallurgy. There are several reasons for its popularity in practice. First of all, TRS is very sensitive to porosity levels. When porosity level is high, TRS values will be not only poor but also very inconsistent. Therefore, it has historically being used as an indicator of the quality of sintered composite materials in manufacturing. Secondly, because of its sensitivity to pores and other defects, TRS is often also viewed as a measure of "toughness".

The effect of diamond $\mathrm{V}_{\mathrm{f}} \%\left(10^{-30}\right)$ in the $\mathrm{Cu}$ matrix on the TRS was studied and the values were listed in Table 6. According to the data obtained, the TRS increases with increasing the diamond $\mathrm{V}_{\mathrm{f}} \%$ in the $\mathrm{Cu}$ matrix and attains the optimum values at $20 \%$.

One can notice that the TRS of the $\mathrm{Cu} /$ coated diamond composites are much higher than those made from $\mathrm{Cu} / \mathrm{uncoated}$ diamond composites. This can be explained by the fact that, the coated layer which consists of carbides and borides acts as crack propagation layer that transfer the strength of diamond to the copper matrix and

Table 6. The TRS values for the investigated composites.

\begin{tabular}{cc}
\hline Investigate Composites & TRS Values, $/ \mathbf{m m}^{2}$ \\
\hline $\mathrm{Cu} /$ uncoated diamond & 210.00 \\
$\mathrm{Cu} / 10 \mathrm{~V} \%$ uncoated diamond & 238.00 \\
$\mathrm{Cu} / 15 \mathrm{~V} \%$ uncoated diamond & 250.00 \\
$\mathrm{Cu} / 20 \mathrm{~V} \%$ uncoated diamond & 270.00 \\
$\mathrm{Cu} / 30 \mathrm{~V} \%$ uncoated diamond & \\
$\mathrm{Cu} / \mathrm{coated}$ diamond with NiWB & 438.65 \\
$\mathrm{Cu} / 10 \mathrm{~V} \%$ coated diamond & 753.37 \\
$\mathrm{Cu} / 15 \mathrm{~V} \%$ coated diamond & 755.00 \\
$\mathrm{Cu} / 20 \mathrm{~V} \%$ coated diamond & 652.60 \\
$\mathrm{Cu} / 30 \mathrm{~V} \%$ coated diamond &
\end{tabular}


also permit a good adhesion between the diamond and the copper matrix that gives more density and less porosity, consequently more strengthened composite. But in case of the uncoated diamond composite, there is no real bonding between diamond and copper matrix, so the adhesion force is very weak, which creates space bonding that deteriorate the strength of the composite.

But if we view the fracture process during TRS testing as consisting of crack initiation and propagation processes and assume the ideal case when the effects of porosity is negligible, the crack initiation process will dominate when the hardness is high and the fracture toughness is very low. Therefore the higher the hardness is, the higher the stress that is needed for crack initiation and hence the higher the TRS. This means that, the TRS of the investigated $\mathrm{Cu}$ /coated diamond is much greater than the $\mathrm{Cu}$ /uncoated diamond. The explanation of the result is as follows; in $\mathrm{Cu} /$ coated diamond the crack resistance is greatest in the coating film, followed by the $\mathrm{Cu}$ grains and the $\mathrm{Cu} /$ diamond interface. The coating grains act to impede rapid crack growth and absorb more energy than the uncoated diamond, thus increasing the fracture toughness of the material.

The fracture micrographs of the investigated materials are shown in Figure 5. Figures 5(a) and (b) indicate the fracture surface of the $\mathrm{Cu}$ /uncoated diamond composite at low and high magnification respectively. Figure 5(b) illustrates poor bonding on (111) diamond surfaces with $\mathrm{Cu}$ matrix as shown in XRD analysis. Marked A in Figure 5(b) indicates regions where the $\mathrm{Cu}$ matrix has adhered to diamond surfaces. This adhesion between $\mathrm{Cu}$ and diamond was consistently observed on (220) diamond faces as described by P. W. Ruch et al. [6]. Figures 5(c) and (d) show the fracture surface of the $\mathrm{Cu} /$

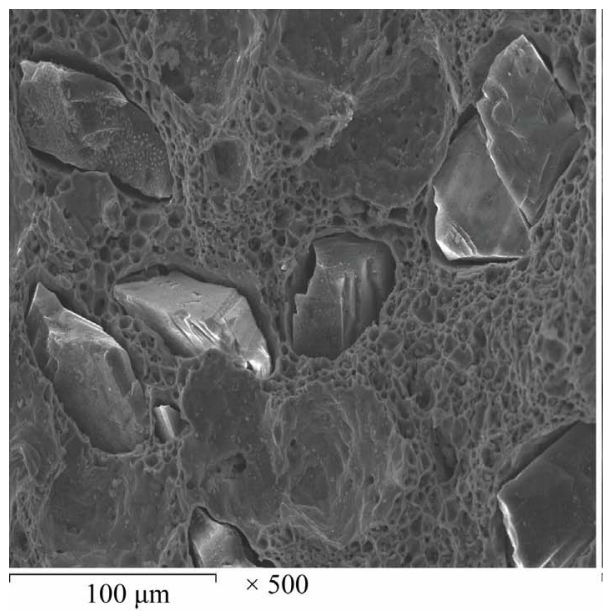

(a)

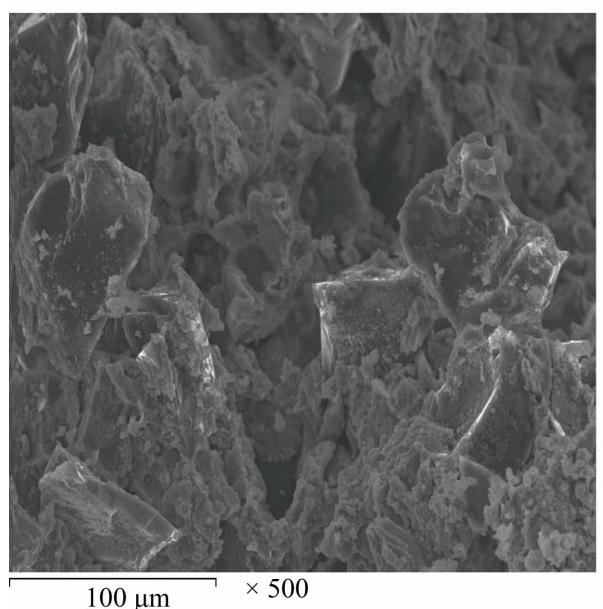

(c)

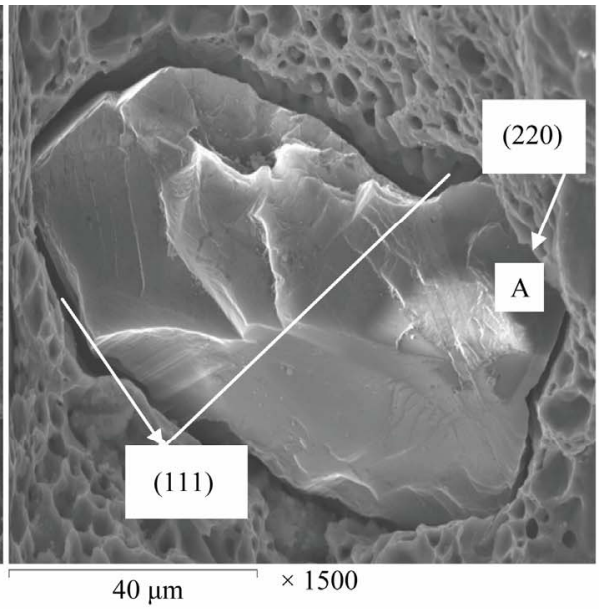

(b)

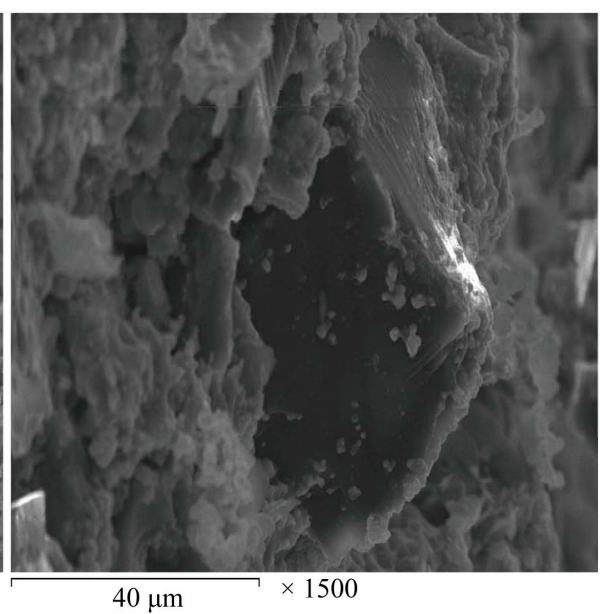

(d)

Figure 5. SEM micrograph of the fracture surface of $\mathrm{Cu} /$ uncoated and coated diamond composite, where (a) $\mathrm{Cu}$ /uncoated diamond at low magnification, (b) at high magnification, (c) $\mathrm{Cu} / \mathrm{NiWB}$ coated diamond composite at low magnification, and (d) $\mathrm{Cu} / \mathrm{NiWB}$ coated diamond composite at high magnification. 
NiWB coated diamond composite at low and high magnification respectively. Figure 5(d) illustrates the improving in the adhesion force between coated diamond surface and $\mathrm{Cu}$ matrix. NiWB coated diamond acts as a filler continuous layer that decreases the pores at the interface and so gives a degree of adhesion that increases the strength of the final composite.

\subsubsection{Thermal Conductivity and CTE of Investigated Composites}

Table 7 shows the variation of thermal conductivity and CTE of pure $\mathrm{Cu}$ and different composites with optimum $\mathrm{V}_{\mathrm{f}} \%$ diamond $\left(20 \% \mathrm{~V}_{\mathrm{f}}\right)$. It is clear that thermal conductivity increased from 378 for $\mathrm{Cu}$ /uncoated diamond composite to $430 \mathrm{~W} / \mathrm{mk}$ for $\mathrm{Cu} /$ coated diamond composites. This means that coated diamond improved the thermal conductivity of the $\mathrm{Cu} /$ diamond composite. Adding uncoated diamond particles to $\mathrm{Cu}$ matrix caused slight increase $(378 \mathrm{~W} / \mathrm{mK})$ in the thermal conductivity of pure $\mathrm{Cu}$. The low thermal conductivity of this composite was indicating a high thermal barrier resistance. This result due to separation between copper and diamond, i.e. diamond particles are surrounded by cavities, which lead to low chemical affinity between copper and diamond. Therefore, it is difficult to produce a bond of low thermal resistance and high mechanical strength between the matrix and the reinforcement. While adding NiWB coated diamonds lead to increase the thermal conductivity of the composites, which demonstrated the effectiveness of the coated layer to obtain a good thermal contact between the matrix and the diamond particles.

Thermal expansion coefficient of copper/diamond composites, namely, $\mathrm{Cu} / 20 \mathrm{~V}_{\mathrm{f}} \%$ uncoated diamond and $\mathrm{Cu} / 20 \mathrm{~V}_{\mathrm{f}} \%$ coated diamond was measured. It can be seen that the CTE of $\mathrm{Cu} /$ coated diamond decreases to 6 $\times 10^{-6} \mathrm{~K}^{-1}$, which is about one-third of that of the pure copper $\left(17 \times 10^{-6}\right)$. The lower CTE of $\mathrm{Cu} /$ coated diamond composite is related to the good bonding between the metal matrix and the diamond particle. This indicates that NiWB coated diamond are a promising reinforcement to lower the CTE of heat sink materials.

\section{CONCLUSIONS}

1) Diamond powders can be coated with NiWB alloy by electroless technique.

2) The sintered materials made from coated powders exhibit better structure homogeneity, higher densification, electrical resistivity, hardness and TRS properties than those made from mixed powders.

3) This work demonstrates that high thermal conductivities can be achieved for $\mathrm{Cu} /$ coated diamond compos-
Table 7. Thermal conductivity and CTE of the investigated composites.

\begin{tabular}{ccc}
\hline Investigate Composites & $\begin{array}{c}\text { Thermal conductivity, } \\
(\mathrm{W} / \mathrm{mk})\end{array}$ & $\mathrm{CTE}, 10^{-6} / \mathrm{k}$ \\
\hline Pure copper & 352 & 17 \\
$\mathrm{Cu} / 20 \mathrm{~V} \%$ uncoated diamond & 378 & 10 \\
$\mathrm{Cu} / 20 \mathrm{~V} \%$ coated diamond & 430 & 6 \\
\hline
\end{tabular}

ite. The formation of a carbide and boride layer is crucial to enable the manufacturing of $\mathrm{Cu} /$ diamond heat sinks with high thermal conductivities up to about $430 \mathrm{~W} / \mathrm{mK}$ combined with CTE of $6 \times 10^{-6} / \mathrm{K}$.

4) Further work address some critical characteristics of composites, in order to promote a better coupling of matrix and reinforcement, thus leading to improved physical and mechanical characteristics.

\section{REFERENCES}

[1] Ellsworth, M.J. (2004) Chip power density and module cool technology projections for the current decade. Proceedings of the 9th Intersociety Conference on Thermal and Thermo Mechanical Phenomena in Electronic Systems, Las Vegas, 2, 707-708.

[2] Zweben, C. (1998) Advances in composite materials for thermal management in electronic packaging. Journal of Management, 50, 47-51.

[3] Zweben, C. (2001) Thermal management and electronic packaging applications. ASM Handbook, 21, 1078-1084.

[4] German, R.M., Hens, K.F. and Johnson, J.L. (1994) Powder metallurgy processing of thermal management materials for microelectronic applications. International Journal of Powder Metallurgy, 30, 205-215.

[5] Evans, T.C. (1998) Thermal properties of electronic materials. Thermal Management Handbook for Electronic Assemblies, McGraw-Hill, New York.

[6] Ruch, P.W., Beffort, O., Kleiner, S., Weber, L. and Uggowitzer, P.J. (2006) Selective interfacial bonding in $\mathrm{Al}(\mathrm{Si})$-diamond composites and its effect on thermal conductivity. Composites Science and Technology, 66, 2677-2685. doi:10.1016/j.compscitech.2006.03.016

[7] Clyne T.W. (2000) Thermal and electrical conduction in MMCs. In: Kelly, A., Chou, T.W., Talreja, R., Clyne, T.W., Warren, R., Carlsson, L., et al., Eds., Comprehensive Composite Materials. Metal-Matrix Composites, Elsevier, Amsterdam, 3.

[8] Weber, L. and Tavangar, R. (2007) On the Influence of active element content on the thermal conductivity and thermal expansion of $\mathrm{Cu}-\mathrm{X}(\mathrm{X}=\mathrm{Cr}, \mathrm{B})$ diamond composites. Journal of Materials Science, 57, 988-991.

[9] Schubert, T., Ciupinski, Ł., Zielinski ,W., Michalski, A., Weigärber, T. and Kieback, B. (2008) Interfacial characterization of $\mathrm{Cu}$ /diamond composites prepared by powder metallurgy for heat sink application. Scripta Materialia, 58, 263-266. doi:10.1016/j.scriptamat.2007.10.011

[10] Schubert, T.H., Ciupiński, Ł., Morgiel, J., Weidmüller, H., Weissgärber, T. and Kieback, B. (2007) Advanced com- 
posite materials for heat sink applications. Euro PM 2007PM Functional Materials, Toulouse, 15-17 October 2007.

[11] Lowenheim, F.A. (1974) Modern electroplating. John Wiley and Sons, New York.

[12] Metal Powder Industries Federation, Princeton (1998).

[13] Fang, Z. and Eason, J.W., (1993) Nondestructive evaluation of WC-Co composites using magnetic properties. International Journal of Powder Metallurgy, 29, 259265.

[14] Deborah, C.D.L. (2001) Applied materials science application of engineering materials in structural, electronics, thermal and other industries. Chapman and Hall, London.

[15] Moustafa, S.F., Abdel, H.Z., Osama, B.G. and Hussien, A. Synthesis of WC hard materials using coated powders. Advanced Powder Metall, 22, 596-601.

[16] Saito, T., Sato, E., Matsuoka, M. and Iwakura, C.J., (1998) Electroless deposition of Ni-B, Co-B and N-Co-B alloys using dimethyl amineborane as a reducing agent. Applied Electrochemistry, 28, 559-563. doi:10.1023/A:1003233715362

[17] Osaka ,T. Takano, N., Kurokawa, T., Kaneko, T. and Ueno, K. (2003) Characterization of chemically-deposited NiB and NiWB thin films as a capping layer for ULSI application. Surface and Coatings Technology, 169-170, 124-127. doi:10.1016/S0257-8972(03)00186-5

[18] Duhin, A., Sverdlov, Y., Feldman, Y. and Shacham-Diamand, Y. (2009) Electroless deposition of NiWB alloy on p-type $\mathrm{Si}(100)$ for NiSi contact metallization. Electrochimica Acta, 54, 6036-6041. doi:10.1016/j.electacta.2009.01.062

[19] Mallory, G.O. (1971) The electroless nickel plating bath: effect of variables on the process. Plating, 58, 319-322.

[20] Mallory, G.O. and Hadju, J.B. (1991) Electroless plating: Fundamentals and applications. AESF, Orlando.

[21] Abdel, A.A., Barakat, H., Abdel, H.Z. (2008) Synthesis and characterization of electroless deposited $\mathrm{Co}-\mathrm{W}-\mathrm{P}$ thin films as diffusion barrier layer. Surface \& Coatings Technology, 202, 4591-4597. doi:10.1016/j.surfcoat.2008.03.023

[22] Pearlstein, F. and Weightman, R.F. (1974) Electroless cobalt deposition from acid baths. Journal of The Electrochemical Society, 121, 1023-1028. doi.org/10.1149/1.2401971

[23] Ellis, D.L. and McDanels, D.L. (1993) Thermal Conductivity and thermal expansion of graphite fiber-reinforced copper matrix composites. Metallurgical and Materials Transactions A, 24, 43-52. doi:10.1007/BF02669601

[24] Abdel, G. and El-Kad, O. (2005) Improvement of wettability of carbon fiber by in-situ carbide coating. Ph.D. Thesis, Cairo University, Cairo.

[25] Khattab, N.M.M. (2001) Ph.D. Thesis, Department of Chemistry, Faculty of Girls, Ain Shams University, Cairo. 